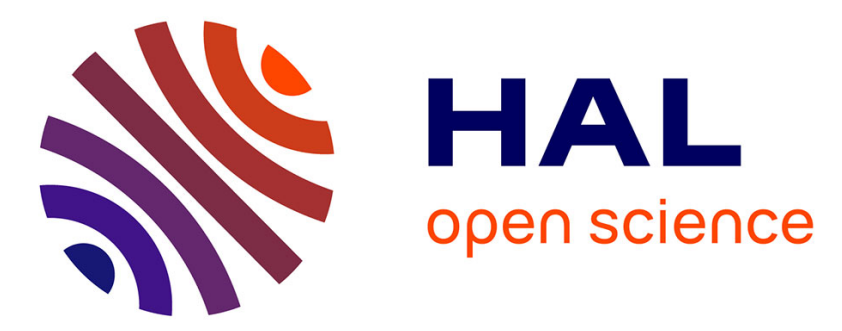

\title{
Conversion of polycyclic aromatic hydrocarbons to graphite and diamond at high pressures
}

V.A. Davydov, A.V. Rakhmanina, V. Agafonov, B. Narymbetov, Jean-Paul Boudou, H. Szwarc

\section{- To cite this version:}

V.A. Davydov, A.V. Rakhmanina, V. Agafonov, B. Narymbetov, Jean-Paul Boudou, et al.. Conversion of polycyclic aromatic hydrocarbons to graphite and diamond at high pressures. Carbon, 2005, 42, pp.261-269. 10.1016/j.carbon.2003.10.026 . bioemco-00156848

\section{HAL Id: bioemco-00156848 https://hal-bioemco.ccsd.cnrs.fr/bioemco-00156848}

Submitted on 22 Jun 2007

HAL is a multi-disciplinary open access archive for the deposit and dissemination of scientific research documents, whether they are published or not. The documents may come from teaching and research institutions in France or abroad, or from public or private research centers.
L'archive ouverte pluridisciplinaire HAL, est destinée au dépôt et à la diffusion de documents scientifiques de niveau recherche, publiés ou non, émanant des établissements d'enseignement et de recherche français ou étrangers, des laboratoires publics ou privés. 


\title{
Conversion of polycyclic aromatic hydrocarbons to graphite and diamond at high pressures
}

\author{
V.A. Davydov ${ }^{\text {a }}$, A.V. Rakhmanina ${ }^{\text {a }}$, V. Agafonov ${ }^{\text {b }}$, B. Narymbetov ${ }^{\text {b }}$, J.-P. Boudou ${ }^{\text {c }}$, , \\ H. Szwarc ${ }^{\mathrm{d}}$ \\ a Institute for High Pressure Physics of the RAS, 142190 Troitsk, Moscow Region, Russia \\ ${ }^{\mathrm{b}}$ Laboratoire de Chimie Physique, Faculte de Pharmacie, Universite de Tours, EA 2098 PIMIR, 37200 Tours, France

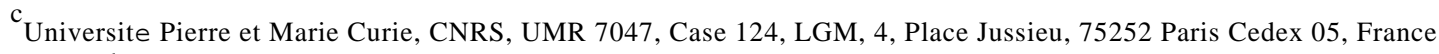 \\ ${ }^{\mathrm{d}}$ Laboratoire de Chimie Physique, Universite Paris Sud, CNRS, UMR 80, Batiment 490, 91405 Orsay, France
}

\begin{abstract}
The polycyclic aromatic hydrocarbons (PAH): naphthalene, anthracene, pentacene, perylene, and coronene were submitted to temperatures up to $1500{ }^{\circ} \mathrm{C}$ at $8 \mathrm{GPa}$. To avoid catalytic action of metals on thermal conversion, graphite was used as container material. Moreover, graphite is very permeable to the gaseous products of thermal decomposition of PAH. The resulting thermal transformations and their evolution were studied by X-ray diffraction, Raman spectroscopy and scanning electron microscopy as a function of temperature for 60-s treatments. The nature of the initial compounds clearly affects the products of the different stages of carbonization and the first steps of graphitization. This becomes hardly discernible in the final stages of graphitization above 1000 ${ }^{\circ} \mathrm{C}$. Above $1200{ }^{\circ} \mathrm{C}$, graphite with high crystallinity forms in all cases. The temperature of the beginning of diamond formation does not seem to be influenced by the nature of the initial PAH and is equal to $-1280{ }^{\circ} \mathrm{C}$ for all investigated compounds. Diamonds formed from the PAH are high-quality 5-40 pm single crystals. The $\mathrm{P}, \mathrm{T}$ values of diamond formation here obtained are significantly lower than those previously known for direct graphite-diamond transformation.
\end{abstract}

Keywords: A. Graphite, Diamond; B. High pressure, Carbonization, Graphitization

\section{Introduction}

Many investigations have been devoted to the study of the thermal transformations of organic compounds at atmospheric pressure. It was shown that these transformations represent a complicated sequence of physicochemical processes that are usually classified under two headings-carbonization and graphitization. Carbonization which occurs at temperatures up to 1000 ${ }^{\circ} \mathrm{C}$ includes processes such as polymerizations, polycondensations, cracking reactions, molecular rearrangements, hydrogen transfers etc. leading to pure carbon materials with various degrees of ordering by gradual loss of hydrogen and other chemical elements

$$
141 .
$$

*Corresponding author. Tel.: +33-1-44-275-142; fax: 33-1-44-275-

E-mail address: jpboudou@ccr.jussieu.fr (J.-P. Boudou).
$[1,2]$. During the graphitization stage, these metastable carbon states evolve towards graphite, an equilibrium state of the carbon system, through gradual annealing of structural defects at temperatures up to $3000-3200{ }^{\circ} \mathrm{C}$ [3-5].

The action of pressure on the carbonization and graphitization of organic compounds has also been studied several times. Although most of these investigations were carried out at rather low pressures, not exceeding $1 \mathrm{GPa}$, they clearly proved that pressure considerably influences all steps of both carbonization and graphitization.

In the case of carbonization, pressure favours polymerizations and, as such, increases the yields of carbon residues. Pressure changes the conditions of the mesophase formation by increasing the viscosity of the liquid medium, thus acting upon the structure of the carbon residue [6,7]. Furthermore, pressure makes possible the solidphase carbonization of organic compounds, so 
that application of high pressures accelerates the graphitization process and results in considerable reduction of the temperature of graphite formation.

In the case of polycyclic aromatic hydrocarbons (PAH), the pressure influence on carbonization and graphitization of naphthalene and anthracene have been studied most extensively [1,2,5-11]. The study of naphthalene carbonization [10] has shown that, at $8 \mathrm{GPa}$, graphite formation occurs very rapidly (within seconds) at only $1000{ }^{\circ} \mathrm{C}$, to be compared with $2500-3000{ }^{\circ} \mathrm{C}$ at atmospheric pressure. Increasing the treatment time at 8 $\mathrm{GPa}$ results in a further decrease of the graphite formation temperature. But the main feature of the thermal conversions of organic compounds under high pressures is that they can be carried out in two different $p$, T ranges, those of thermodynamic stability of graphite or of diamond, respectively. In the latter range, diamond should be the final product of the transformations. So, a new stage--diamond formation--appears in the sequence of thermal transformations of organic compounds under high pressure.

The first attempt to synthesise diamond through treatment of various organic compounds at 12-13 GPa, according to the current pressure scale, and 1300-3000 ${ }^{\circ} \mathrm{C}$ in the absence of a metal-catalyst was made by Wentorf [12]. The work was carried out in a "Belt"' highpressure apparatus using titanium as sample container material. In the course of these studies, Wentorf showed that the final product of the transformations of naphthalene, anthracene, and chrysene at 12 GPa and 2000 ${ }^{\circ} \mathrm{C}$ is graphite, whereas the treatment of adamantane, camphene, pyrene, fluorene, and polyethylene in the same conditions leads to diamond formation with a $-60 \%$ yield. The increase of the synthesis temperature up to $2300{ }^{\circ} \mathrm{C}$ allowed diamond to form from anthracene, but with a rather low yield not exceeding 30\%. Moreover, Wentorf pointed out that the diamonds thus obtained were quite unusual: they were snow-white "soft" diamonds, with the appearance and mechanical properties of paraffin wax or chalk. Nevertheless, the Xray diffraction patterns of these products were those of diamond, but with broadened diffraction lines. Therefore, the transformation had produced very small diamond crystallites. As a result, it was assumed that the very nature of the starting carbonaceous material affects decisively the nature of the products of pyrolysis under pressure, even at $2000{ }^{\circ} \mathrm{C}$ or more. It was also concluded that the synthesis of the usual "hard" diamonds from organic compounds is not possible, at least at pressures up to $12 \mathrm{GPa}$ and temperatures up to $2300{ }^{\circ} \mathrm{C}$. It is to be stressed that the temperature of the direct graphitediamond transformation at $12 \mathrm{GPa}$ found by Wentorf was $1300{ }^{\circ} \mathrm{C}$.

The failure of this first attempt to synthesise "hard" diamond from organic compounds under high static pressures stopped the investigations in this field for a long time. Nineteen years elapsed before Yakovlev et al. reported the possibility of "hard" diamond synthesis from organic compounds: hydrocarbons [13] and carbohydrates [14], at static pressures and without metalcatalysts. Furthermore, the authors $[13,14]$ did not find a well-defined influence of the pristine molecular structures on the final stages of the thermal conversions, although diamond synthesis was performed at $p, T$ values lower than those used in Ref. [12]. A similar result was obtained by Voronov and Rakhmanina on studying nucleation of diamond crystals from $\mathrm{sp}^{2}$ and $\mathrm{sp}_{3}$ hydrocarbons decomposed under high pressure [15].

Later, "direct" diamond synthesis from various precursors including terpene-family hydrocarbons, furfuryl alcohol resin, phenolic resin, and mesophase pitch was studied by Onodera and Suito [16]. They used an octahedral anvil press with tantalum, molybdenum, and Teflon as sample container materials. The authors paid considerable attention to the influence of the content of hydrogen in the starting substances on the pA $T$ parameters of diamond formation and yield. They showed that, when using Ta for the sample container and heater, diamond formation is observed for all hydrocarbons (camphene, adamantane, and fluorene) studied in the 6$12 \mathrm{GPa}$ pressure range at temperatures up to $1600{ }^{\circ} \mathrm{C}$. The lowest $p, T$ values for diamond synthesis (6 GPa and $700{ }^{\circ} \mathrm{C}$ ) were obtained for camphene. They also showed that the threshold pressure for diamond synthesis increases from camphene (6 GPa), to adamantane (8 $\mathrm{GPa})$, and fluorene ( $9 \mathrm{GPa})$. The high threshold value for fluorene was explained by the aromaticity of this compound which necessitates more energy to break the aromatic rings. Thus, it was concluded that the initial hydrocarbon structure affects the $p, T$ parameters of diamond synthesis. The authors pointed out also that the influence of the hydrogen content is not clear for the model hydrocarbons (camphene, adamantane, and fluorene). But, in the cases of furfuryl alcohol resin and mesophase pitch, there are optimal values for the $\mathrm{H} / \mathrm{C}$ atomic ratio which decrease the diamond formation temperature and increase the diamond yield. When some limiting value of the $\mathrm{H} / \mathrm{C}$ ratio is exceeded, diamond formation stops. It is worthy of note that the role of Ta in diamond formation is not conclusively shown because no diamond was formed under the pertinent conditions when Ta, as the container material, was replaced by Mo or by Teflon. Onodera and Suito [16] suggested that Ta facilitates the dehydrogenation process of organic compounds. But, taking into account that Ta is the sole metal which has a catalytic action on the graphite-diamond transformation without the formation of a solution $[17,18]$, it may be assumed that Ta also favours a decrease of the $p, T$ parameters of diamond formation.

The aim of the present work was to get a better understanding of the influence of the starting molecular structure on the thermal conversions of organic com- 
pounds at high pressures. $\mathrm{PAH}$ (naphthalene: $\mathrm{C}_{10} \mathrm{H}_{8}$, anthracene: ${ }_{14410}$, pentacene: $\mathrm{C}_{22} \mathrm{H}_{14}$, perylene: $\mathrm{C}_{20} \mathrm{H}_{12}$, and coronene: $\mathrm{C}_{24} \mathrm{H}_{12}$ and adamantane: $\mathrm{C}_{10} \mathrm{H}_{16}$

were submitted to pressure-treatments at $8 \mathrm{GPa}$ and temperatures up to $1500{ }^{\circ} \mathrm{C}$. In the above compounds, the $\mathrm{H} / \mathrm{C}$ atomic ratio changes from 0.5 for coronene to 0.8 for naphthalene; it is 1.6 for adamantane. To avoid catalytic effects of metals on the conversion processes of these compounds, high-pressure high-temperature treatments were performed in containers made of special 99.9\% pure graphite. The processes of graphite and diamond formations underwent careful scrutiny.

\section{Experimental}

Naphthalene and adamantane (Chemapol, impurity contents less than $0.5 \%$ ) and anthracene, pentacene, perylene, and coronene (Aldrich Chemical Company, impurity contents less than $2 \%$ ) were used without further purification. The work was performed in a "Toroid' '-type high-pressure apparatus [19]. Cylindrical samples of the initial compounds (4 mm diameter and 5 $\mathrm{mm}$ height) previously obtained by cold pressing were put into graphite containers which were placed in the highpressure apparatus. The experimental procedure consisted in loading the apparatus up to $8 \mathrm{GPa}$ at room temperature, heating up to the desired temperature (with a heating rate of $15{ }^{\circ} \mathrm{C}$ per second) at which the samples were then maintained under constant load for $60 \mathrm{~s}$. The resulting high-pressure states were quenched under pressure to room temperature. Temperature was measured during the high-pressure experiments by means of chromelalumel and $\mathrm{Pt}-\mathrm{Pt} / \mathrm{Rh}$ thermocouples. The relative temperature accuracy was equal to ${ }^{ \pm 2}{ }^{\circ} \mathrm{C}$. However, the absolute temperature accuracy above $1200{ }^{\circ} \mathrm{C}$ was about $\pm 50{ }^{\circ} \mathrm{C}$.

The recovered samples were analyzed at ambient conditions by means of X-ray diffraction, Raman spectroscopy and scanning electron microscopy (SEM). Xray diffraction patterns were obtained with an INEL CPS 120 diffractometer using $\mathrm{CuKa}_{1}$ radiation. The Raman spectra were recorded on a Dilor XY spectrometer using the $514.5 \mathrm{~nm}$ emission line of an $\mathrm{Ar}_{\mathrm{p}}$ laser as excitation source. Microscopic investigations were carried out by means of an electron scanning microscope DSM 982 Gemini.

\section{Results}

Fig. 1 shows the X-ray diffraction patterns of the pristine $\mathrm{PAH}$ and products of their treatments at $8 \mathrm{GPa}$ and different temperatures.

According to this figure, the thermal transformations of $\mathrm{PAH}$ are characterized by common features which are also observed for adamantane. First of all, for treatment times not exceeding $60 \mathrm{~s}$, the initial crystalline molecular phases of naphthalene, anthracene, pentacene, perylene, and coronene remain the basic components of the samples up to $400{ }^{\circ} \mathrm{C}$. At $600{ }^{\circ} \mathrm{C}$, in all cases, significant amorphization is observed. A further temperature increase leads to intensive departure of hydrogen and dramatic reconstruction of the treated compounds which begin to lose their initial individuality. At $800{ }^{\circ} \mathrm{C}$, all patterns exhibit mainly two types of peaks: $\left(\begin{array}{lll}0 & 0 & 2\end{array}\right)$ resulting from stacks of parallel layer planes at 23-29\%, and two-dimensional (01) peaks resulting from the regular structure within the individual layer plane segments at $41-47^{\circ}$. Peaks of the type (hkl) are absent, indicating that there is little or no stacking order in the arrangement of parallel layers. These patterns are known to be characteristics of carbon states described as clusters made of small fragments of graphene planes plus some amount of disorganized carbon [3,20,21].

The appearance of three-dimensional (10 0) and (101) peaks at $1000{ }^{\circ} \mathrm{C}$ shows that three-dimensional ordering of the graphene planes takes place and that graphite structure formation begins. The formation of diamond is observed at $1280{ }^{\circ} \mathrm{C}$ for all compounds. In consequence of the existence of a temperature gradient in the high-pressure apparatus, diamond forms first of all in the middle part of the surface of the sample cylinder, that is in the region of the highest temperature. In the lower temperature sample parts, graphite with a high degree of crystalline perfection is obtained. The corresponding diffraction pattern is shown in Fig. 2.

The increase of treatment temperature leads to increased diamond yield which reaches almost $100 \%$ at temperatures above $1350{ }^{\circ} \mathrm{C}$. In all cases, diamond formation occurs within a few seconds. As the absolute accuracy of our temperature measurements above 1200 ${ }^{\circ} \mathrm{C}$ is $\pm 50{ }^{\circ} \mathrm{C}$, we cannot know whether the temperature of the beginning of diamond formation varies significantly from one compound to another.

The variations of the structural parameters vs. temperature for the carbon materials formed during graphitization were determined. Fig. 3 shows the temperature dependences of the distance between graphene planes (d002) and the average sizes of the crystallites, $L_{a}$ and $L_{c}$, where $L_{a}$ and $L_{c}$ are the crystallite sizes in the layer plane and in its normal direction, respectively. The $\mathrm{d}_{002}$ values were determined from the $\left(\begin{array}{lll}0 & 0 & 2\end{array}\right)$ diffraction peak positions. The dimensions of carbon crystallites have been determined from the analysis of X-ray diffraction line broadening. According to the Scherrer formula, $L_{c}$ is equal to:

$L_{c} 1 / 40: 89 k=ð B \cos h_{c} P$ ə1р

where $\mathrm{k}$ is the $\mathrm{X}$-ray wavelength, $\mathrm{B}$ is the angular width (radians) of the $\left(\begin{array}{lll}0 & 0 & 2\end{array}\right)$ diffraction peak at half-maximum intensity (corrected for instrumental broadening) and $h_{c}$ 

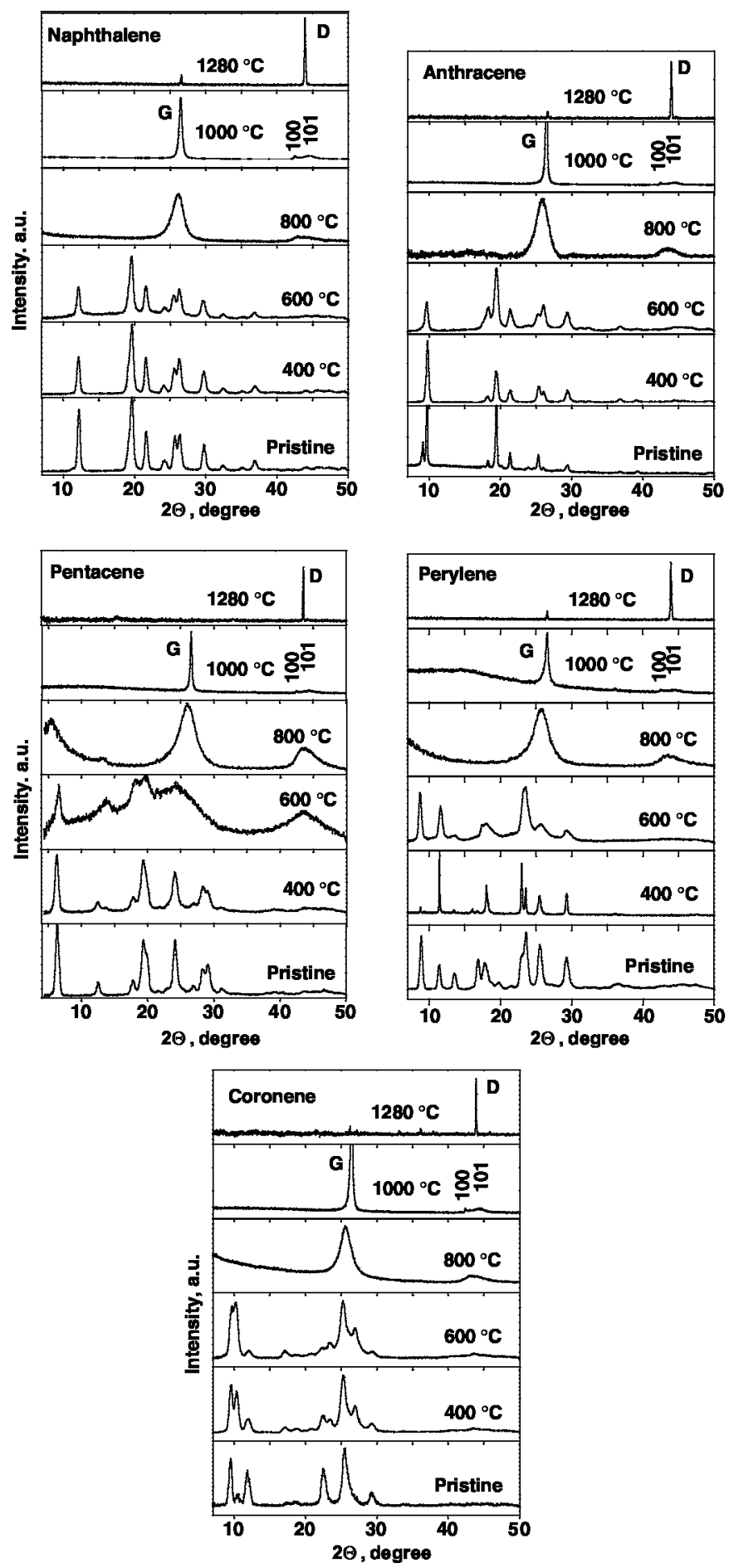

Fig. 1. X-ray diffraction patterns of the samples obtained from naphthalene, anthracene, pentacene, perylene, and coronene vs. treatment temperatures at $8 \mathrm{GPa}$ for $60 \mathrm{~s}$. G and D correspond to the graphite (002) and diamond (111) diffraction peaks, respectively.

is the Bragg angle for reflection (002) [21]. The layer dimension $\mathrm{L}_{\mathrm{a}}$ is calculated by use of the equation:

\section{La $1 / 41: 84 k=ð B \cos h_{a} p$}

where $B$ and $h_{a}$ correspond to reflections (10) and (10 0) [21].
As shown in Fig. 3, evidences for two-dimensional carbon clusters formation appear at $700{ }^{\circ} \mathrm{C}$.

In the $700-1000{ }^{\circ} \mathrm{C}$ temperature range, the dooz values for high-pressure states formed from perylene and coronene are systematically larger than those for states formed from naphthalene, anthracene, and pentacene at the same temperature. This demonstrates the influence 


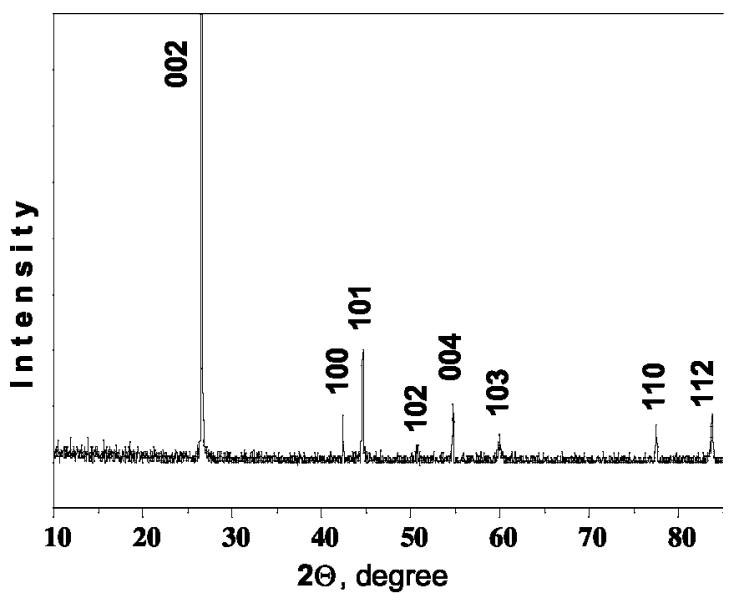

Fig. 2. X-ray diffraction pattern of graphite obtained as a result of treatment of naphthalene at $8 \mathrm{GPa}$ and the nominal temperature of $1280{ }^{\circ} \mathrm{C}$.
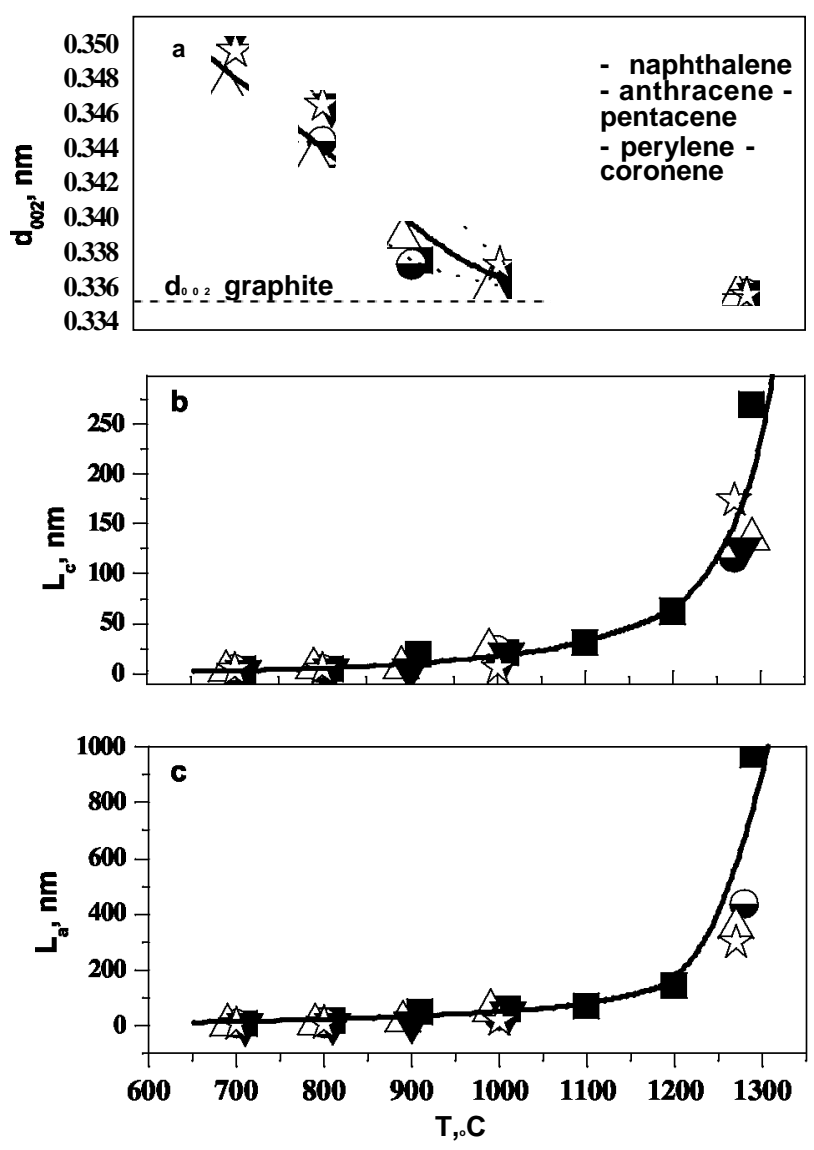

Fig. 3. Temperature dependences of the do02, $L_{c}$ and $L_{a}$ values for carbonaceous materials obtained through PAH treatment at $8 \mathrm{GPa}$ for $60 \mathrm{~s}$. Dotted lines in (a) show the upper and lower values of the do02 values in the $700-1100{ }^{\circ} \mathrm{C}$ temperature range. Two horizontal dashed lines show the door values corresponding to the states of turbostratic carbon $(0.3440 \mathrm{~nm})$ and ideal graphite $(0.3354 \mathrm{~nm})$ that are the initial and final states of graphitization. of the initial PAH structures on the thermal conversion products. Assuming that the ${ }_{\mathrm{d} 0}$ value for graphitization onset is equal to $0.344 \mathrm{~nm}[3-5,21]$, the graphitization process for linear-condensed $\mathrm{PAH}$ begins at lower temperatures than for perylene and coronene (see Fig. 3a).

According to Fig. $3 \mathrm{~b}$ and $\mathrm{c}$, the crystallite sizes increase sharply above $1150{ }^{\circ} \mathrm{C}$. The validity of the $\mathrm{L}_{\mathrm{a}}$, $\mathrm{L}_{c}$ calculation methods is questionable for temperatures above $1150{ }^{\circ} \mathrm{C}$ where the crystallite sizes are larger than $100 \mathrm{~nm}$. However, in Fig. 3, we presented also the crystallite sizes calculated from the X-ray data for graphite formed at the nominal temperature of $1280{ }^{\circ} \mathrm{C}$ which is the lowest temperature of diamond formation at $8 \mathrm{GPa}$. According to our results, graphite samples with do02 $1 / 4$ 0:3354 $\mathrm{nm}$ (which corresponds to the interplanar distance of perfect graphite) are formed at temperatures higher than $1150{ }^{\circ} \mathrm{C}$ from all PAH.

The SEM photographs of Fig. 4 show the evolution of the morphologies of the materials formed at different temperatures. Fig. 4a exhibits a characteristic example of the stratified structures resulting from PAH treatments (here perylene) at $8 \mathrm{GPa}$ and $700{ }^{\circ} \mathrm{C}$. When temperature increases, the layered character of the materials develops. Fig. 4b-d display typical views of graphite and diamond particles, respectively, obtained from PAH transformations (here naphthalene) at $8 \mathrm{GPa}$ and the nominal temperature of $1280{ }^{\circ} \mathrm{C}$.

From graphite views recorded at $1100{ }^{\circ} \mathrm{C}$ and above, we could not distinguish any influence of the initial substances (PAH and adamantane) on the products of the final stages of carbonization. Graphite obtained near the lowest diamond formation temperature is composed of platelets with rounded edges. Their sizes are equal to 3-30 lm for $L_{a}$ and 0.1-0.3 lm for $L_{c}$ (Fig. $4 \mathrm{~b}$ and c). In this case, X-ray and SEM measurements are in good agreement for the $L_{c}$ values. But as expected, the X-ray $L_{a}$ values appear much smaller than those determined through SEM.

The diamond crystal sizes are equal to -5-35 $1 \mathrm{~m}$ (Fig. 4d). As a whole, the diamond crystals have greater sizes than the graphite particles from which they are formed. The SEM views of Figs. 4d and 5 show the sample regions with near total and partial diamond formation, respectively. The partial diamond formation is associated with the existence of the above-mentioned temperature gradient in the reaction zone. Fig. 5 allows to note an interesting feature of the diamond formation manifesting itself at "direct" synthesis of diamonds from hydrocarbons. At micron-scale, the untransformed graphite and the diamond crystals occur in distinct regions. Graphite platelets are frequently oriented perpendicular to the growing diamond facets.

Raman spectra were also studied in the same temperature range and those corresponding to materials obtained from naphthalene are displayed in Fig. 6. 

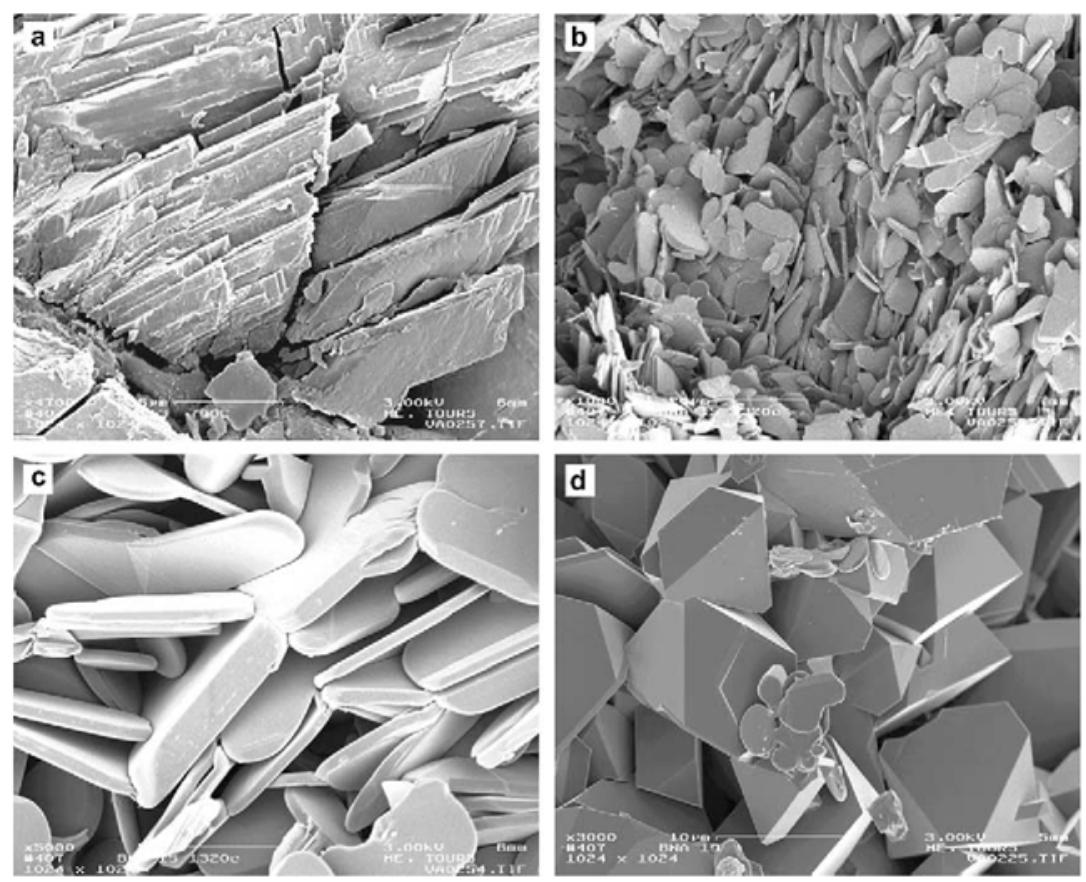

Fig. 4. SEM photographs of materials obtained as a result of high-pressure high-temperature treatment of perylene--8 GPa and $700{ }^{\circ} \mathrm{C}$ (a) and naphthalene- $8 \mathrm{GPa}$ and $1280^{\circ} \mathrm{C}(\mathrm{b}-\mathrm{d})$.

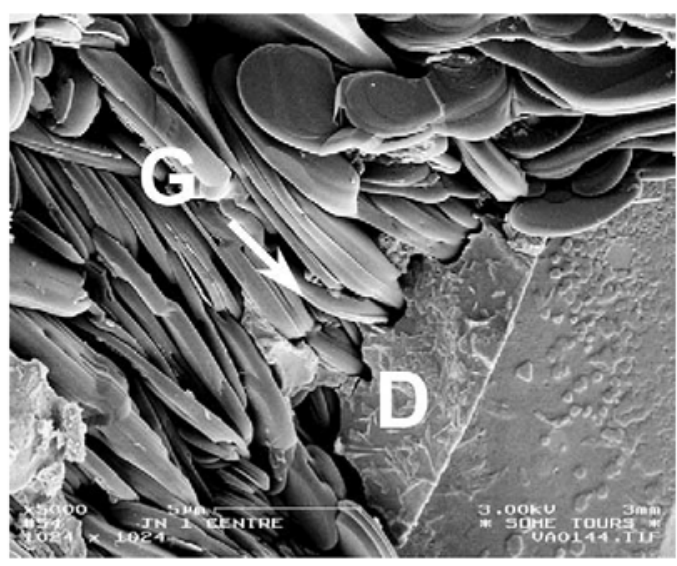

Fig. 5. SEM photograph of the contact zones between graphite particles (G) and diamond (D) obtained as a result of treatment of naphthalene at $8 \mathrm{GPa}$ and the nominal temperature of $1280^{\circ} \mathrm{C}$. The arrows show the dominant direction of graphite particles orientation about the growing diamond facets.

Similar evolutions are observed for others PAH. But in the case of naphthalene, we can compare our data with the results of a recent study of carbon materials formed through carbonization of a naphthalene-derived mesophase pitch at atmospheric pressure [22]. Comparison of the latter results with those obtained as a result of thermal conversions of naphthalene-derived pitches at 8 GPa confirms that high pressures reduce considerably both temperature and time of treatment necessary to reach any given carbonization or graphitization stage. This is especially true in the case of graphitization. So,

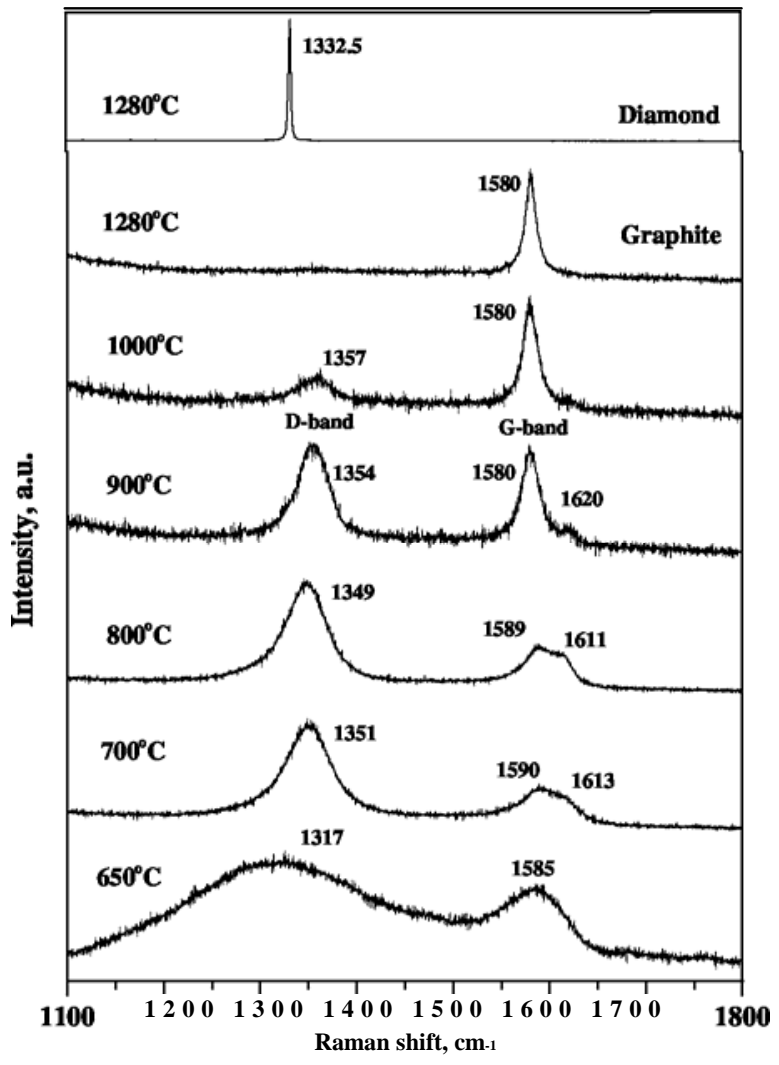

Fig. 6. Raman spectra of the materials obtained by treatment of naphthalene at $8 \mathrm{GPa}$ and different temperatures.

such states as observed at $900{ }^{\circ} \mathrm{C}$ and $8 \mathrm{GPa}$ (Fig. 6) form only at $2080{ }^{\circ} \mathrm{C}$ at atmospheric pressure [22]. 
Furthermore, the structural quality of the graphite obtained at $8 \mathrm{GPa}$ and $1000{ }^{\circ} \mathrm{C}$ is far better than that obtained at atmospheric pressure and $2700{ }^{\circ} \mathrm{C}$.

The evolution of the Raman spectra exhibited in Fig. 6 can be interpreted in terms of a three-stage model recently suggested by Ferrari and Robertson for the interconversion between amorphous carbon states and graphite [23]. This model takes into account changes of positions and intensities of the $G$ and $D$ bands [24,25]. The changes of the $\mathrm{G}$ band positions (initial shift up to 1592 $\mathrm{cm}^{-1}$ and subsequent reverse displacement down to 1580 $\mathrm{cm}^{-1}$ ) and the values of the $\mathrm{I}(\mathrm{D}) / \mathrm{I}(\mathrm{G})$ ratio (initial increase almost up to 3 and subsequent decrease almost to 0 at $1280{ }^{\circ} \mathrm{C}$ ) correspond perfectly to the final stages of " an ordering trajectory", of a carbon system in the course of its transformation from amorphous carbon to graphite [23]. According to this model, the first stage of spectrum evolution in the $600-800{ }^{\circ} \mathrm{C}$ temperature range (Fig. 6), related to the final steps of carbonization, corresponds the formation of nanocrystalline graphite. As this takes place, the fraction of $\mathrm{sp}_{3}$ carbon states in the system tends to 0 . The second stage, associated with graphitization, corresponds to transformation of nanocrystalline graphite into microcrystalline graphite. The $\mathrm{X}$-ray data illustrate this process very well.

\section{Discussion}

The results of this work constitute one more verification that high pressures affect radically all stages of the thermal conversion of hydrocarbons. In the following discussion, we will concentrate on three questions:

- The reasons of the discrepancies regarding the diamond synthesis parameters as determined in this study and in Refs. [12,16].

- The influence of the nature of the starting hydrocarbons on the diamond synthesis parameters and the limits of hydrogen content, above and below which diamond synthesis does not occur in the investigated $\mathrm{p}$, $\mathrm{T}$ range.

- Mechanisms of diamond formation from hydrocarbons in the absence of metal-catalysts.

As noted above, the minimum $\mathrm{p}, \mathrm{T}$ values for diamond synthesis from $\mathrm{PAH}$ and adamantane obtained in this work (8 GPa and $1280{ }^{\circ} \mathrm{C}$ ) are much lower than those reported by Wentorf [12] for anthracene (12 GPa and $2300{ }^{\circ} \mathrm{C}$ ), adamantane (12 GPa and $2000{ }^{\circ} \mathrm{C}$ ) and other hydrocarbons; the pressure value $(8 \mathrm{GPa})$ is even somewhat lower than that ( $9 \mathrm{GPa}$ ) obtained by Onodera and Suito for diamond synthesis from fluorene in the case of a Ta container [16]. In our opinion, these discrepancies arise from thermodynamic constraints. They are related to the choice of the container material and to its permeability for the gaseous products of hydrocarbon pyrolysis. The importance of this factor was already noted by Yakovlev in his analysis of thermodynamic conditions of diamond formation from hydrocarbons [26]. As a container material, graphite has a much higher permeability for the gaseous component and primarily for hydrogen than metals or Teflon. The greater issue of hydrogen from the reaction zone in the case of the carbon container ensures the greater degree of the $\mathrm{PAH}$ decomposition, the greater yield of the carbon residue, and consequently the greater yield of diamond. That is, thermal conversions in graphite capsules take place in the conditions of more open system. For this reason, higher $p, T$ values are needed for an achievement of the same degrees of hydrocarbons decomposition and of the same diamond yield in the cases of the Ti, Mo or Teflon containers. According to our data, the total mass loss near $1280{ }^{\circ} \mathrm{C}$, say for naphthalene, is equal to $-25 \%$. This mass loss in the dehydrogenation process coincides with the data of Ref. [10] and correlates formally with complete departure of hydrogen in the form of methane. Diamond synthesis in Ta containers [16] can probably be explained by the catalytic action of Ta and may be by the higher permeability to gaseous products of the Ta capsule in comparison with the Ti, Mo or Teflon capsules $[12,16]$.

In our experiments, we did not observe any pronounced influence of the starting molecular structure of organic compounds on the parameters of diamond formation. Starting with $\mathrm{H} / \mathrm{C}$ atomic ratios ranging from 0.5 to 1.6 , we did not find an upper limit of the hydrogen content for diamond formation. For all investigated aromatic compounds and adamantane, diamond formation at $8 \mathrm{GPa}$ begins practically at the same temperature of $-1280{ }^{\circ} \mathrm{C}$. The starting $\mathrm{H} / \mathrm{C}$ ratio rather acts upon the diamond yield and on the sizes of the resulting diamond crystallites. However, from the results obtained by Onodera and Suito [16], it may be assumed that the existence of such an upper limit is possible at least for two reasons. The first one has a thermodynamic origin and is related to the choice of the container material as is discussed above. Materials with high gastightness induce confinement of the gaseous products of thermal conversion in the reaction zone. It interferes with an attainment of high degrees of the $\mathrm{PAH}$ decomposition and of a significant yield of the carbon residue--a necessary component for the diamond synthesis. On the other hand, when the gaseous products can leave the reaction zone, a very high content of hydrogen in the initial carbonaceous material can induce a very important decrease of the system volume at the stage of carbon residue formation. Thus, the pressure in the reaction zone can decrease below the one which is necessary for diamond synthesis in the conditions of fixed press load. 
It is to be stressed that, during our experiments, it was observed that diamond is formed not only from the carbonaceous product of the hydrocarbons carbonization, but also from the graphite of the container walls in contact with this carbonization product. Thus, graphitediamond transformation in the presence of products of the hydrocarbon carbonization is observed at $p_{;} T$ values which are much lower than the known minimum parameters of direct graphite-diamond transformation, that are $12 \mathrm{GPa}$ and $3000{ }^{\circ} \mathrm{C}$ [27], $12 \mathrm{GPa}$ and $1300{ }^{\circ} \mathrm{C}$ [12], $11.5 \mathrm{GPa}$ and $3000{ }^{\circ} \mathrm{C}$ [28], and $14 \mathrm{GPa}$ and $800{ }^{\circ} \mathrm{C}$ [29]. In experiments with homogeneous graphitehydrocarbon mixtures, we have tried to determine the minimum hydrogen content for which diamond formation at $8 \mathrm{GPa}$ is still possible. It was shown that almost complete conversion of all carbon lying in the reaction zone, including graphite and carbon formed by carbonization of hydrocarbons, takes place if the hydrogen mass content in the starting mixture is equal to $1 \%$. Fig. 7 shows diamond formed at $8 \mathrm{GPa}$ and $1280{ }^{\circ} \mathrm{C}$ from binary mixtures of graphite with naphthalene and anthracene with this hydrogen content.

Decrease of hydrogen mass content below $1 \%$ reduces the diamond yield. When the hydrogen mass content is below $0.2 \%$, no diamond is formed. Complete transformation of carbonaceous material into diamond is also observed when the initial hydrogen mass content increases above $1 \%$. But in this case, the diamond produced becomes gradually looser and looser and easily breaks down into separate crystals and splinters when extracted from the high-pressure apparatus. The increase of porosity of the diamond product is obviously related to the increase of the density jump undergone by carbonaceous materials when diamond forms from the mixtures with high hydrogen contents.

These results suggest that hydrogen plays an important role in the processes of diamond formation from graphite and carbon residues resulting from hydrocarbon carbonization at high pressures. It is known that the hydrogen content decreases gradually in the course of the co-carbonization of hydrocarbons with graphite. During the final steps of carbonization, the chemically bound hydrogen atoms are mainly gathered in the defective graphite sheets [21]. An analogous promoting effect of hydrogen on the high-pressure synthesis of diamond was noted by Kindlein et al. [30] who showed that the implantation of hydrogen ions in graphite allows to obtain a $50 \%$ increase of diamond nucleation during the high-pressure graphite-diamond transformation. The interpretation of these results is not straightforward. Further investigation is currently being performed in our group by using high resolution transmission-electron microscopy and related techniques to provide insight into the understanding of the hydrogen action mechanism on the direct transformation of graphite to diamond.
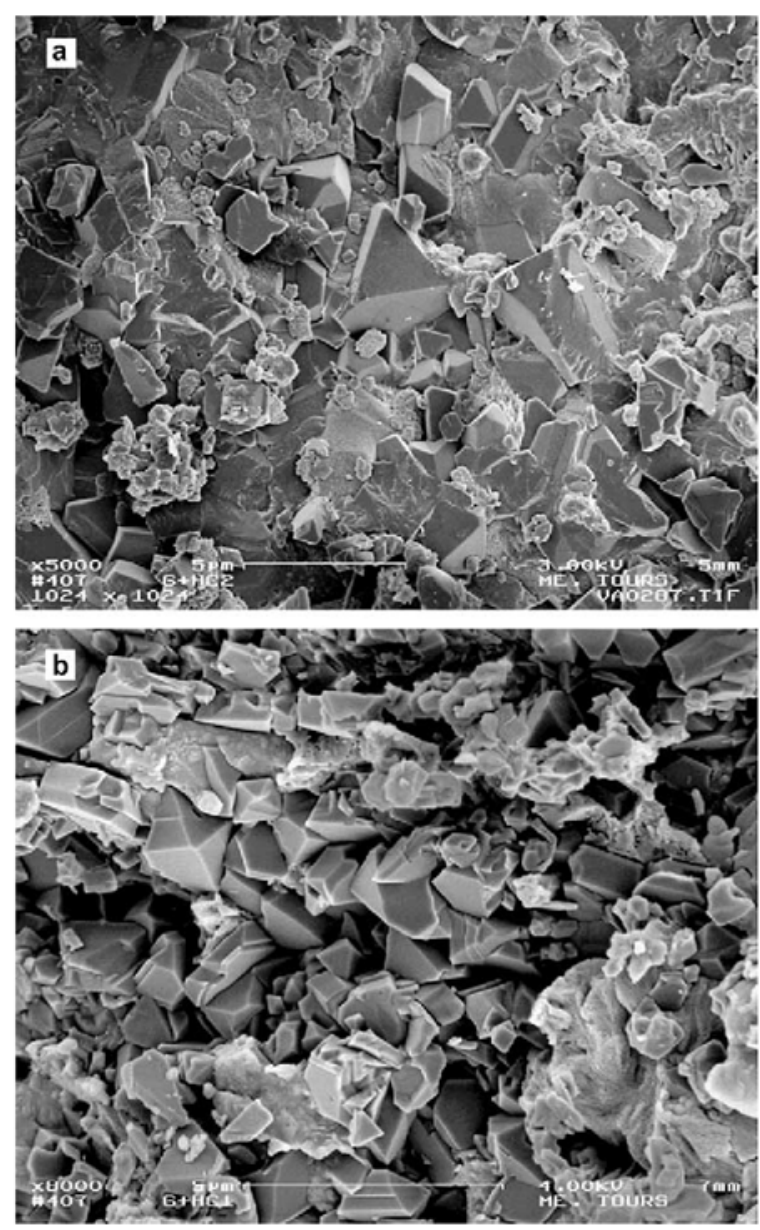

Fig. 7. SEM photographs of diamond materials obtained by treatment of binary mixtures of graphite with naphthalene (a) and with anthracene (b) under $8 \mathrm{GPa}$ and $1280{ }^{\circ} \mathrm{C}$.

\section{Acknowledgements}

The present work was supported by the Russian Foundation for Basic Research (Grant no. 03-0332640), by Scientific exchange grants (No. 9577 and 12245), from CNRS and the Russian Academy of Sciences, and by NATO Science Program (Grant PST.CLG.979714) Financial support from CNRS Programme Materiaux (Project No. 114) is gratefully acknowledged. We thank L.S. Kashevarova and L.F. Afanaseva for the help in high-pressure experiments.

\section{References}

[1] Fitzer E, Mueller K, Schaefer W. The chemistry of the pyrolytic conversion of organic compounds to carbon. In: Walker Jr PL, editor. Chemistry and Physics of Carbon, vol. 7. New York: Dekker; 1971. p. 237-383.

[2] Walker Jr PL. Carbon: an old but new material revisited. Carbon 1990;28(2/3):261-79.

[3] Franiklin RE. The interpretation of diffuse X-ray diagrams of carbon. Acta Cryst 1950;3:107-21. 
[4] Franklin RE. Crystallite growth in graphitizing and non-graphitizing carbons. Proc Roy Soc A 1951;209:196-218.

[5] Fischbach DB. The kinetics and mechanism of graphitization. In: Walker Jr PL, editor. Chemistry and Physics of Carbon, vol. 7. New York: Dekker; 1968. p. 1-105.

[6] Whang PW, Dachille F, Walker Jr PL. Pressure effects on the initial carbonization reactions of anthracene. High Temp-High Press 1974;6(2):127-36.

[7] Whang PW, Dachille F, Walker Jr PL. Pressure effects on the structure of carbons produced from anthracene. High Temp-High Press 1974;6(2):137-47.

[8] Marsh A, Dachille F, Melvin J, Walker Jr PL. The carbonization of anthracene and biphenyl under pressures of $300 \mathrm{MN} \mathrm{m}^{-2}$ (3 kbar). Carbon 1971;9(2):159-77.

[9] Ayache J, Oberlin A, Inagaki M. Mechanism of carbonization under pressure. Carbon 1990;28(2):337-51.

[10] Voronov OA, Rakhmanina AV. Kinetics of naphthalene carbonization at pressure of 8 GPa. Russ Inorg Mater 1992;28(7):1408- 13.

[11] Davydov VA, Kashevarova LS, Revin OG. Kinetics of the initial stages of naphthalene pyrolytic conversion at high pressures. Russ J Phys Chem 1996;70(6):1012-5.

[12] Wentorf RH. The behaviour of some carbonaceous materials at very high pressures and high temperatures. J Phys Chem 1965;69(9):3063-9.

[13] Yakovlev EN, Voronov OA, Rakhmanina AV. Diamond synthesis from hydrocarbons. Sverkhtverd Mater 1984;59(4):811 [in Russian].

[14] Yakovlev EN, Shalimov MD, Kulikova LF, Slesarev VN. Diamond synthesis from carbonhydrates. Russ J Phys Chem 1985;59(6):1517-8.

[15] Voronov OA, Rakhmanina AV. Nucleation of diamond crystals from the $\mathrm{sp}^{2}$ and $\mathrm{sp}^{3}$ hydrocarbons decomposed under high pressure. In: Proceedings, 5th International Symposium on Diamond Materials, Electrochemical Society, Pennington, NJ, USA, 1998. p. 197-200.

[16] Onodera A, Suito K. Synthesis of diamond from carbonaceous materials. In: Manghanani MH, Nellis WJ, Nicol MF, editors. Science and technology of high pressure. Proceedings of AIRAPT-17. Hyderabad, India: Universities Press;
[18] Bovenkerk HP, Bundy FP, Hall HT, Strong HM, Wentorf Jr RH. Preparation of diamond. Nature 1959;184(4693):1094-8.

[19] Giardini AA, Tydings JE. Diamond synthesis: observations on the mechanism of formation. Am Mineralogist 1962;47(11/12):1393421.

[20] Khvostantsev LG, Vereshchagin LF, Novikov AP. Device of toroid type for high pressure generation. High Temp-High Press 1977;9(6):637-9.

[21] Ruland W. X-ray diffraction studies on carbon and graphite. In: Walker Jr PL, editor. Chemistry and physics of carbon, vol. 4. New York: Dekker; 1968. p. 1-84.

[22] Kinoshita K. Carbon: electrochemical and physicochemical properties. New York: John Wiley and Sons; 1988. p. 31-4.

[23] Dumont M, Chollon G, Dourges MA, Pailler R, Bourrat $\mathrm{X}$, Naslain $\mathrm{R}$, et al. Chemical, microstructural and thermal analysis of a naphthalene-derived mesophase pitch. Carbon 2002; 40(9):1475-86.

[24] Ferrari AC, Robertson J. Interpretation of Raman spectra of disordered and amorphous carbon. Phys Rev B 2000; 61(20):14095-107.

[25] Tuinstra F, Konig JL. Raman spectrum of graphite. J Chem Phys 1970;53(3):1126-30.

[26] Fitzer E, Rozploch F. Some remarks on Raman spectroscopy of carbon structures. High Temp-High Press 1988;20(4):449-54.

[27] Yakovlev EN. Thermodynamic conditions for diamond formation from hydrocarbons. Sverkhtverd Mater 2001;5(5):14-8 [in Russian].

[28] Bundy FP. Direct conversion of graphite to diamond in static pressure apparatus. Science 1962;137(3535):1057-8.

[29] Vereshchagin LF, Ryabinin ON, Semertsan AA, Lifshits LD, Demyashkevich BP, Popova SV. Direct graphite-diamond transformation at high static pressures. Russ Dokl Acad Nauk SSSR 1972;206(1):78-9.

[30] Endo S, Idani N, Oshima R, Takano KJ, Wakatsuki M. $\mathrm{X}$-ray diffraction and transmission-electron microscopy of natural polycrystalline graphite recovered from high pressure. Phys Rev B 1994;49(1):22-7.

[31] Kindlein Jr W, Livi RP, Balzaretti NM, da Jordana JAH. Effect of hydrogen implantation on graphite used in high-pressure diamond synthesis. Diam Rel mater 2000;9(1):22-5. 